Original Article

\title{
PREDICTORS OF LEFT VENTRICULAR REMODELING IN PATIENTS WITH ST- ELEVATION MYOCARDIAL INFARCTION TREATED BY PRIMARY PERCUTANEOUS INTERVENTION
}

\author{
Mahmoud Hassan shah, Nader talat kandil, Wael ali ali, Alaa Ramadan Mohamed \\ Cardiology Department, Faculty of Medicine, Zagazig University, Zagazig, Egypt
}

\section{Corresponding Author: \\ Alaa Ramadan Mohamed \\ Cardiology Department, \\ Faculty of Medicine, \\ Zagazig University, \\ Zagazig, Egypt \\ dr.alaarmy@yahoo.com}

Submit Date 2019-01-30

Revise Date 2019-02-19

Accept Date 2019-03-04

\section{ABSTRACT}

Background: Outcomes in the treatment of STEMI have markedly improved in recent years. However, LV remodeling is still commonly present in MI patients. Early prediction of LV remodeling in MI patient is a matter of challenge.

Aim of the study: is to highlight the value of certain factors that may help in early prediction of LV remodeling after STEMI eg; ECG parameters, GLS, biomarker NT-pro BNP and angiographic factors like TIMI and MBG.

Patients and Methods: The study included 60 patients 1st acute STEMI directed, all patients were subjected to ECG analysis, admission time and GLS , NT-pro BNP, LV volume and EF, pulsed Doppler and TDI and 3 months follow up NT-pro BNP, LV volume and EF, pulsed Doppler and TDI , angiographic parameters were assessed TIMI and MBG

Results: there was a statistically significant difference between the study groups regarding, male sex, sum STR, incomplete STR, GLS, 3 months LVED and EF, three vessel disease, MBG, there was positive correlation between GLS and LV remodeling ( $r=0.643, p<0.001)$, there was strong negative correlation between sum STR and LV remodeling ( $\mathrm{r}=-0.494, \mathrm{p}<0.001)$ A ROC analysis was performed. The cut-off value of GLS that predict LV remodeling was $-15.6 \%$ multivariate regression analysis showed that GLS was an independent predictor of LV remodeling.

Conclusions: Global Longitudinal strain can significantly predict adverse LV remodeling early after MI at a cut-off value $-15.6 \%$.

Keywords: LV remodeling, GLS, Predictors

\section{INTRODUCTION}

M yocardial elevation

injury caused by STmyocardial infarction (STEMI)leads to left ventricular remodeling, leading to functional and structural left ventricular changes [1]. Also remodeling worsely impair cardiac function and resulting in marked morbidity and mortality [2]. To decrease left ventricular remodeling, early risk stratification is needed to allow monitoring and aggressive management of high-risk patients.

The most commonly assessed functional left ventricular characteristic to June 2019 Volume 25 Issue 3 predict patient outcome after MI is left ventricular ejection fraction [3]. Marked structural left ventricular features have also shown to be reliable predictors of cardiac events and mortality, including left ventricular end diastolic volume, end systolic volume, although there is limited information of the predictive value of electrocardiographic, novel deformation indices, biochemical and angiographic factors.

The aim of our work is to highlight the value of certain factors that may help in early prediction of left ventricular remodeling after www.zumj.journals.ekb.eg 
primary percutaneous intervention (PCI) eg; electrocardiographic parameters, novel two dimensional speckle tracking echocardiography derived global longitudinal strain (2D-STE derived GLS), novel biomarker parameter like $\mathrm{N}$ terminal pro brain nareuritic peptide ( NT-pro BNP) and the role of angiographic factors like Thrombolysis In Myocardial Infarction (TIMI) flow grade and myocardial blush grade (MBG) .

\section{Patients:}

\section{PATIENTS AND METHODS}

The study included 60 patients $1^{\text {st }}$ acute STEMI defined as having ischaemic chest pain $\geq 30$ minutes, $S T$ elevation $>1 \mathrm{~mm}$ in $\geq 2$ contiguous leads on the limbs or $>2 \mathrm{~mm}$ in $\geq 2$ precordial contiguous leads [4], directed to cath lab for primary PCI.

\section{Exclusion criteria of the study:}

- Refusal to sign consent.

- ST-segment elevation myocardial infarction onset to primary percutaneous intervention time $>12 \mathrm{hrs}$.

- Previous myocardial infarction (MI)) or coronary artery bypass graft (CABG).

- Presence of other significant heart disease (marked valvular dysfunction, cardiomyopathy)

- Presence of non-cardiac disease that decrease life expectancy.

- Thrombolytic therapy during ST-segment elevation myocardial infarction.

\section{Ethical consideration:}

Written consent was obtained from every patient after explanation of the procedure. Medical research and ethics committee of Zagazig University approved the study. The work was carried out in accordance with The Code of Ethics of the World Medical Association (Declaration of Helsinki) for studies involving humans.

Patients were divided into two groups according to percentage of changes in left ventricular end diastolic volume (LVED) volume at admission and three month follow up, after that patients who showed $\geq 20 \%$ changes in LVED volume were defined to have LV remodeling while patients who showed $<20 \%$ changes in LVED volume didn't have LV remodeling; so group (I) $=25$ cases no left ventricular remodeling ( $\mathrm{LVr}$ ) and group (II) $=35$ cases had (LVr).
All patients were subjected to: Complete history taking, full general and local cardiac examination,

ECG analysis: ECG machine was used to record standard 12-lead ECGs. They were recorded at a paper speed of $25 \mathrm{~mm} /$ second (s) and a $10 \mathrm{~mm} / \mathrm{mv}$ calibration. Twelve-lead electrocardiography was performed directly before and 60-90 min after infarct related artery (IRA) recanalization. Sum of STR was calculated as sum of ST-segment elevation on the first ECG minus the sum of the STsegmet elevation on the second ECG divided by the sum of ST segment elevation on the first ECG and expressed as a perentage [5]. The ST segment resolution (STR) was categorized as complete $(\geq 70 \%)$ and incomplete $(\leq 70 \%)$ [6], infarct territory weather inferior, anterior or posterior

Blood sampling and measurement of NT pro BNP: was assessed at two moments admission time and 3 months later at follow up visit arranged at outpatient clinic to assess the level of NT pro BNP whether increasing or decreasing from the admission time and in which group these changes occurred, An enzyme immunoassay technique was used (Elecsys 2100, Roche Diagnostics).The following NT-pro BNP are considered abnormal if: Higher than $450 \mathrm{pg} \backslash \mathrm{ml}$ for patients under age of 50 years. Higher than $900 \mathrm{pg} \backslash \mathrm{ml}$ for patients age 50 and older was found [7].

Echocardiography: Two examinations were done; the first is immediately with admission time and the $2^{\text {nd }}$ after 3 months from primary (PCI) with exception that (STE) study was performed only a admission time. Resting echocardiography study and STE were performed using the Vivid 9 system (GE Vingmed Ultrasound AS, Horten, Norway). ): The LV volumes and ejection fraction (EF) were assessed using the modified Simpson biplane technique from the apical 4- views, Normally EF between 50-70\% [8]. After 3 month follow up: 2D LV volumes was reassessed with the result of contractility change from the first study and three months in form of: $\mathrm{Lv}$ remodeling: indicated significant LV volume dilatation at baseline and 3-month study No Lv remodeling: indicated LV volume dilatation at baseline but 
decreased or normalized after 3-month study. The definition of remodeling, following definitions from other publications, was an LVEDV increase of $>20 \%$ compared with the echocardiographic study performed at baseline [9].

Pulsed doppler of mitral inflow: Apical $4 \mathrm{CV}$ with align the Doppler beam with inflow direction, place a 1-3 mm PW Doppler sample volume between the mitral leaflets tips where the following measurements were taken: The peak early E wave (peak early diastolic velocity) in $\mathrm{cm} / \mathrm{s}$. The peak late $A$ wave (peak late atrial filling rate) in cmls. E\A ratio (relative contribution of early and late atrial filling [10].

\section{Color- flow M-mode Doppler ,flow} propagation (vp) velocity assessment: Apical 4CV, magnified to encompass the LV. Color Doppler flow from $\mathrm{M}$ annulus into the LV. M-mode cursor aligned with color inflow.Color M-mode, at sweep speed of $100 \mathrm{~mm} / \mathrm{s}$. Shift the color flow baseline to lower the Nyquist limit so that the central highest velocity jet is blue. Slope the first aliasing velocity during early filling, measured from mitral valve plane to approx $4 \mathrm{~cm}$ distally into the LV cavity, or the transition from no color to color. With Vp less than $50 \mathrm{cmls}$ is considered abnormal and the ratio of peak $\mathrm{E}$ velocity to $\mathrm{Vp}$ is also measured which is directly related to LA pressure and therefore EIVP $>1.5$ denoting high LA pressure [11].

Tissue Doppler diastolic velocities: were measured from the septal, lateral, inferior, and anterior mitral annuli in the 2- and 4-chamber views and averaged. The following measurements were recorded: early diastolic velocity $\left(\mathrm{e}^{\prime}\right)$. The ratio of early diastolic mitral inflow velocity (E) to tissue Doppler imaging (TDI) e' (E/e'), which correlates with diastolic filling pressure, was considered. With average $\left(\mathrm{E} / \mathrm{e}^{\prime}\right)$ value $\leq 8$ is considered grade $\mathrm{I} \geq 14$ grade III, 9-13 grade II [12].

Strain echocardiography (STE) using the speckle tracking technique: Longitudinal strain was measured for each LV segment using the apical three, four and two chamber views. The LV endocardial border was traced using the optimal frame for endocardial identification in all three apical views, and the automatically created region of interest was manually adjusted to the thickness of the myocardium. Subsequently, numeric and graphical bulls eye displays of deformation parameters were automatically generated for all LV segments [13]. Average value of global longitudinal strain $(\boldsymbol{G} \boldsymbol{L S})$, less than (20\%) is considered abnormal, [14].

Angiographic finding: Invasive intervention was done for all patients by professional team using (GE medical system manufactured by SIMENSE, Kemnath $\backslash$ Germany) by using the dye-filled guiding catheter as a reference. Left and right guiding catheter was introduced through the sheath in right femoral artery (transfemoral approach). Wiring the closed culprit artery (defined as; [TIMI] flow grade 0) and restored blood flow after pPCI (TIMI] flow grade III where bare metal stent (BMS) were used in all cases. Revascularization of the culprit artery only was done unless the patient was on cardiogenic shock. [15]. However TIMI 3 flow doesn't result in effective myocardial reperfusion, myocardial blush grade (MBG) is a better angiographic measure of myocardial perfusion so (MBG) was assessed post primary (PCI) [16]. Severity of the lesion was visually evaluated by eyeballing of two experienced interventional cardiologist, where the coronary artery narrowing was visually estimated and expressed as percentage of luminal diameter stenosis. Patients with $\geq$ $70 \%$ narrowing in left anterior descending (LAD), circumflex artery(LCX) or right coronary artery(RCA) or their major branches and $\geq 50 \%$ in left main coronary were classified as having significant angiographic coronary artery disease[17].

\section{Statistical analysis}

Statistical analysis was done using the following tests: paired $\mathrm{t}$ test, chi squere, pearson correlation, ROC curve, univariate and multivariate logistic regression test.

\section{RESULTS}

Regarding to demographic data, the present study showed that, there was statistical significant difference between the study groups regarding male sex in favor of group (II) $p$ value $<0.05$ but there was no significant difference regarding age, hypertension, diabetes mellitus, obesity, dyslipidemia ) $p$ 
value $>0.05$ (table 1 ).

There was statistical significant difference between the study groups regarding sum STR and incomplete STR $p$ value $<0.05$, but there was no significant difference between the study groups regarding maximum ST elevation and MI territory $p$ value $>0.05$.table $(1 \mathrm{~s})$

There was non significant difference between the study groups regarding NT-prop BNP at admission and 3 month follow up $p$ value > 0.05 (table 2s).

There was high statistical significant difference between the study groups regarding, GLS $p$ value $<0.001$ but there was non-significant difference regarding admission time EDV,ESV,EF, Ele E\A.VP and ElVp p value > 0.05 (table $3 \mathrm{~s}$ ).

There was statistical significant difference between the study groups regarding 3 months follow up $\mathrm{EDV}$, and $\mathrm{EF} \quad p$ value $<0.05$, but there was non significant difference regarding $\mathrm{E} \backslash \mathrm{A}$, Ele , Vp and Elvp $p$ value $>0.05$ (table $4 \mathrm{~s})$.

There was statistical significant difference between the study groups regarding, $\triangle \mathrm{EDV}$, $\Delta \mathrm{EF} \mathrm{p}$ value $<0.05$ but there was non significant difference regarding, $\Delta$ ESV $p$ value $>0.05$ (table 2).

There was high statistical significant difference between the study groups regarding three vessel disease $p$ value $<0.001$, but there was no significant difference regarding single and two vessels disease $p$ value $>0.05$ (table $5 \mathrm{~s}$ ).
There was non statistical significant difference between the study groups regarding baseline TIMI flow $p$ value $>0.05$ (table 6s).

There was non statistical significant difference between the study groups regarding post PPCI TIMI flow grades $p$ value $>0.05$ (table $7 \mathrm{~s}$ ). There was high statistical significant difference between the study groups regarding MBG $p$ value $<0.001$ (table $8 \mathrm{~s}$ ).

There was strong negative correlation between sum STR and LV remodelin $(\mathrm{r}=-0.494, \mathrm{p}<$ 0.001) (figure 1).

There was positive correlation between GLS and LV remodeling $(r=0.643, p<0.001)$ (figure 2).

A ROC analysis was performed. The cut-off value of GLS that predict LV remodeling was $15.6 \%$ (AUC $=0.91$, CI $95 \%$ ranged from 0.845 to 0.991 , sensitivity $=88.6 \%$, specificity $=$ $80 \%$ ) (figure 3 ).

Bland -Altman plot test, to detect whether there is a difference between 2 measurements of GLS, the test was non significant $p$ value $=0.411$ denoting no interobserver variability ( figure 1s).

By applying univariate then multivariate regression analysis we found that GLS was an independent predictor of $\mathrm{LV}$ remodeling in STEMI patients after primary PCI while, $\mathrm{MBG}$ and incomplete STR, Sex , $\triangle$ EDV and three vessel disease failed to predict the $\mathrm{LV}$ remodeling (table $3 \& 4$ ).

Table 1. Demographic data and risk factors of the study groups

\begin{tabular}{|c|c|c|c|c|}
\hline & $\begin{array}{l}\text { Group }(I) \\
(\text { no } \\
\text { remodeling) } \\
(\mathbf{n = 2 5})\end{array}$ & $\begin{array}{l}\text { Group }(\text { II) } \\
(\mathrm{LV} \text { remodeling } \\
(\mathrm{n}=35)\end{array}$ & $\begin{array}{l}\text { Test } \\
\text { value }\end{array}$ & p-value \\
\hline $\begin{array}{l}\text { Age (years) } \\
\bar{X}_{ \pm S D}\end{array}$ & $55.12 \pm 6.60$ & $56.60 \pm 10.95$ & 0.60 & $>0.05$ \\
\hline $\begin{array}{rl}\text { Gender } & F=(\%) \\
M & n(\%)\end{array}$ & $\begin{array}{l}17(68 \%) \\
8(32 \%)\end{array}$ & $\begin{array}{l}13(37.1 \%) \\
22(62.9 \%)\end{array}$ & 5.5 & $\leq 0.05$ \\
\hline HTN n $(\%)$ & $16(64 \%)$ & $17(48.6 \%)$ & 1.4 & $>0.05$ \\
\hline DM n (\%) & $14(56 \%)$ & $26(74.3 \%)$ & 2.1 & $>0.05$ \\
\hline Smoking n (\%) & $12(48 \%)$ & $16(45.7 \%)$ & 0.03 & $>0.05$ \\
\hline Obesity n (\%) & $12(48 \%)$ & $16(45.7 \%)$ & 0.03 & $>0.05$ \\
\hline Dyslipidemia n (\%) & $12(48 \%)$ & $17(48.6 \%)$ & 0.002 & $>0.05$ \\
\hline
\end{tabular}

M: Male, F: Female, HTN: Hypertension, DM: diabetes, $\overline{\mathrm{X}}=$ mean , SD= standard deviation 
Table 2. $\Delta$ change in EDV, ESV and EF in the study groups

\begin{tabular}{|l|l|l|l|l|}
\hline \multirow{2}{*}{$\Delta$ change } & $\begin{array}{l}\text { Group (I) } \\
(\mathbf{n = 2 5})\end{array}$ & $\begin{array}{l}\text { Group (II) } \\
(\mathbf{n}=\mathbf{3 5})\end{array}$ & $\begin{array}{l}\text { Test } \\
\text { value }\end{array}$ & p-value \\
\cline { 1 - 4 } & Mean \pm SD & Mean \pm SD & \\
\hline EDV ml & $7.26 \pm 4.714$ & $45.32 \pm 4.646$ & $\mathbf{- 6 . 1}$ & $\underline{\underline{0.001}}$ \\
\hline ESV ml & $2.71 \pm 3.73$ & $8.20 \pm 3.47$ & $\mathbf{3 . 4}$ & $>0.05$ \\
\hline EF \% & $2.54 \pm 0.5$ & $12.2 \pm 1.1$ & $\mathbf{3 . 9}$ & $\underline{\mathbf{0 . 0 5}}$ \\
\hline
\end{tabular}

EDV:end diastolic volume, ESV:end systolic volume,EF:ejection fraction

Table 3. Univariate logistic regression analysis for predictors of LV remodeling .

\begin{tabular}{|c|c|c|c|c|c|c|}
\hline & 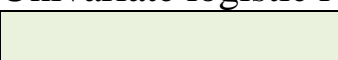 & \multirow[t]{2}{*}{ B } & \multirow{2}{*}{$\begin{array}{l}\text { Sig.( } \\
\text { value })\end{array}$} & \multirow[t]{2}{*}{$\operatorname{Exp}(B)$} & \multicolumn{2}{|c|}{$95.0 \%$ C.I for $\operatorname{EXP}(B)$} \\
\hline & & & & & Lower & Upper \\
\hline & Male sex & 1.100 & $<\mathbf{0 . 0 3}$ & 3.005 & 1.997 & 4.522 \\
\hline & $<70 \%$ STR & 1.440 & 0.013 & 4.222 & 1.356 & 13.150 \\
\hline & \begin{tabular}{|ll} 
GLS & (cut-off \\
$15.6)$
\end{tabular} & 3.434 & $<0.001$ & 31.0 & 7.419 & 129.528 \\
\hline & $\Delta \mathrm{EDV}$ & 6.521 & $<0.001$ & 1.4 & 0.98 & 1.89 \\
\hline & $\begin{array}{|ll|}\begin{array}{l}\text { Three } \\
\text { disease }\end{array} & \text { vessel } \\
\end{array}$ & 1.253 & $<0.001$ & 0.286 & 0.081 & 1.012 \\
\hline & MBG 2 & 1.933 & $<0.001$ & 6.909 & 2.160 & 22.098 \\
\hline
\end{tabular}

Table 4. Multivariate regression analysis to discover the predictors of LV remodeling.

\begin{tabular}{|c|c|c|c|c|c|}
\hline & \multirow[t]{2}{*}{$\mathbf{B}$} & \multirow{2}{*}{$\begin{array}{l}\text { Sig.( p- } \\
\text { value) }\end{array}$} & \multirow{2}{*}{$\operatorname{Exp}(B$} & \multicolumn{2}{|c|}{$95.0 \%$ C.I for $\operatorname{EXP}(B)$} \\
\hline & & & & Lower & Upper \\
\hline Male Sex & 0.510 & 0.455 & 0.601 & 0.158 & 2.286 \\
\hline$\Delta \mathrm{EDV}$ & 7.880 & 0.066 & 1.23 & 12.613 & 39.918 \\
\hline$<70 \%$ STR & 2.850 & 0.07 & 3.28 & 1.761 & 169.698 \\
\hline GLS (cut-off 15.6) & 4.033 & $\leq 0.001$ & $\begin{array}{l}56.41 \\
3 \\
\end{array}$ & 6.912 & 460.395 \\
\hline $\begin{array}{ll}\text { Three } & \text { vessel } \\
\text { disease } & \end{array}$ & 1.174 & 0.299 & 0.209 & .034 & 2.838 \\
\hline MBG 2 & 2.747 & 0.08 & 4.598 & 2.102 & 115.717 \\
\hline
\end{tabular}




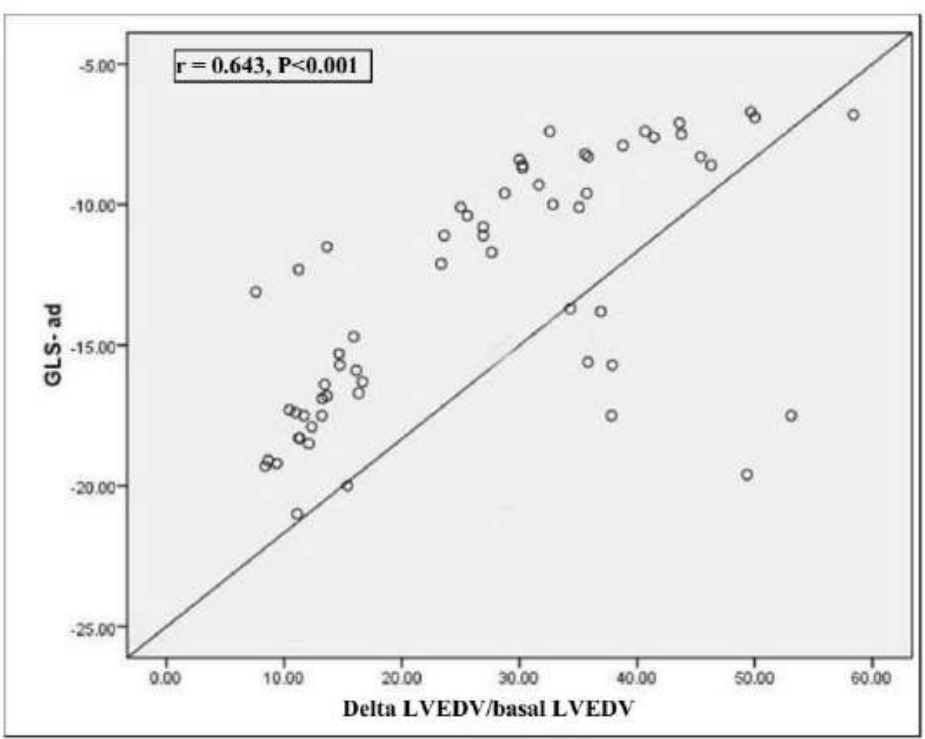

Figure (1): show high statistically significant positive correlation between GLS and LV remodeling defined as (delta change of LVEDV in relation to basal LVEDV) $(r=0.643 p<0.001)$

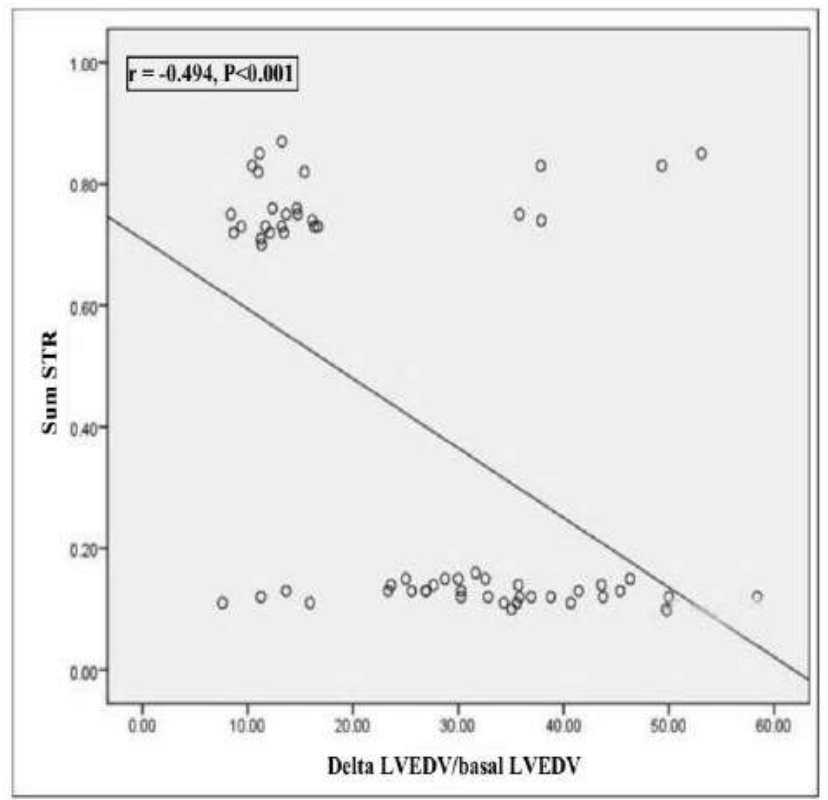

Figure ( 2 ): show high statistically significant negative correlation between sum STR and LV remodeling $(r=-0.494 \mathrm{p}<0.001)$ 


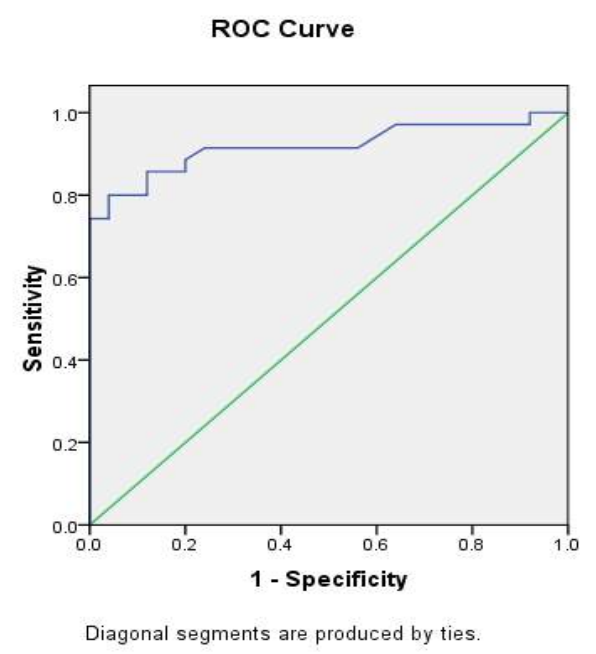

Figure (3) : ROC curves of value of GLS that can predict $L V$ remodeling:

A ROC analysis was performed. The cut-off value of GLS that predict LV remodeling was $-15.6 \%$ $(\mathrm{AUC}=0.91, \mathrm{CI} 95 \%$ ranged from 0.845 to 0.991 , sensitivity $=88.6 \%$, specificity $=80 \%)$

\section{DISCUSSION}

There was statistical significant difference between the study groups male sex in favor of Group (II), this agreed with the fact that there was gender differences in left ventricular remodeling. Post-mortem data suggest that males and females may have a different modulation of the apoptotic pathway. Females appear to be partially protected from ischemia-induced activation of the apoptotic pathway ${ }^{[18]}$

The present study showed significant difference between the study groups regarding percentage of STR, with higher percentage of incomplete STR in LV remodeling group (II). This was concordant with Carrick et al ${ }^{[19]}$ who found statistical significant difference among his study groups with higher percentage of incomplete STR (30\%-70\%) in the third tertile group. This agree with the fact that incomplete STR is markedly related to a higher rate of adverse cardiac events in patients with MI even after successful reperfusion of the culprit artery, which suggested that the microcirculatory perfusion in the infarct area was markedly impaired in these patients even after complete reperfusion of epicardial arteries ${ }^{[20]}$.

Interestingly, the present study showed significant difference between the study groups regarding sum STR which was in favor of group (I), this was powered by the strong negative correlation between sum STR and LV remodeling $(r=-0.494, p<0.001)$, this finding was concordant with Amaya et al ${ }^{[21]}$ who found a significant inverse correlation between the degree of STR and $\triangle$ LVEDV ( $r=$ $-0.576, \mathrm{p} 0.01$ )

The present study showed non significant difference between the study groups regarding NT-pro BNP at admission time( 0 h- $3^{\text {rd }}$ day); although we noticed that there was higher level in group (II) who had LV remodeling . This was concordant with $\mathrm{Na}$ et al ${ }^{[22]}$ who found non significant difference between his group study regarding NT-pro BNP

The present study reassessed the level NT-pro BNP 3 months after MI although this was non significant statistically, we noticed that there was higher level of NT-pro BNP in group (II) who had LV remodeling. The rise in the plasma levels of NT-proBNP overtime in group (II) suggests that myocardial wall stress may have increased during the follow-up period.This was discordant with LópezHaldón et al ${ }^{[23]}$ who found significant difference between his study groups regarding NT-pro BNP, the discrepancies with our study might be explained that he assessed NT-pro BNP 6 months after MI.

Regarding admission time EDV, ESV, EF: the present study showed non significant difference between the study groups, however measurements were impaired in both groups denoting myocardial sunning. This was concordant with Sugano et al ${ }^{[24]}$ who 
found non significant difference between his study groups regarding EDV, ESV and EF.

The present study, showed non significant difference regarding E\A, Ele, VP and E $\backslash V p$, although we noticed impaired parameters in both groups denoting impaired diastolic function, this was concordant with Sugano et al ${ }^{[24]}$ who found no significant difference regarding tissue Doppler measurement Ele in his study groups. Also this was concordant with another study LópezHaldón et al [23] who found no significant difference regarding $\mathrm{V} \backslash \mathrm{P}$ and E\Vp.

Our study showed high statistical significant difference between the study groups regarding admission GLS with lower GLS value in group (II) who developed remodeling, this was concordant with Bastawy et al ${ }^{[25]}$ who found high significant difference between his study groups regarding GLS. Furthermore, this finding was powered by the strong positive correlation between GLS and LV remodeling $(\mathrm{r}=0.643, \mathrm{p}<0.001)$, this was concordant with Bonios et al ${ }^{[26]}$ who found positive correlation between GLS and LV remodeling $(\mathrm{r}=0.56, \mathrm{p}=0.001)$,

Interestingly, we found that GLS can significantly predict $\mathrm{LV}$ remodeling at a cutoff value $-15.6 \%$ (AUC $=0.91, \mathrm{CI} 95 \%$ ranged from 0.845 to 0.991 , sensitivity $=88.6 \%$ specificity $=80 \%$ ), Bastawy et al ${ }^{[25]}$ have concluded that the LV systolic GLS at baseline echocardiographic assessment that can significantly predict remodeling was $12.5 \%$ (Sensitivity $87 \%$, Specificity $85 \%$ ).

Regarding echo data 3 month after MI: The present study showed statistical significant difference between the study groups regarding EDV and EF and we noticed that there was more impairment in group (II) after 3 months in comparison to admission measurements, unlike group (I) which showed improvement in relation to admission parameters, this was concordant with Bonios et al ${ }^{[26]}$ who showed significant difference between his study groups regarding 3 months follow up EDV and $\mathrm{EF}$

Also , the present study showed non significant difference regarding E\A, Ele , Vp and ElvP although we noticed more impairment of these parameters in group (II) denoting worsened diastolic dysfunction after 3 months in comparison to admission measurements, unlike group (I )which showed slight unremarkable change at 3 months in comparison to admission measurements, this finding was discordant with LópezHaldón et $\mathbf{a l}^{[23]}$ who found significant difference between his study groups regarding Ele, indeed he didn't assess E\A, V\P and E\Vp and his measurements were assessed after 6 month follow up this might explain the discrepancies with our study.

The present study showed high significant difference between the study groups regarding three vessel disease with higher percentage in favor of group (II), this was discordant with $\mathbf{X u}$ et al ${ }^{[27]}$ who found no significant difference in his study groups regarding three vessel disease.

The present study showed non significant difference between the study groups regarding baseline TIMI flow, although we noticed that TIMI 0 and TIMI 1 were higher in group(II),this was concordant with $\mathbf{X u}$ et al [27] who found non significant difference in his study groups regarding TIMI flow $<3$.

In additioin. The present study showed non significant difference between the study groups regarding post PPCI TIMI 3 ,although we noticed higher incidence of TIMI 3 in group (II), this was concordant with Khurelsukh et $\mathbf{a l}^{[28]}$ who found non significant difference between his study groups regarding post PPCI TIMI 3. This could be explained by the fact that TIMI flow grade has some limitations as mentioned by de Pardo et al ${ }^{[29]}$ who stated that TIMI flow grade is subjective way and is related to assessment of blood flow in large epicardial arteries only. Ito et al ${ }^{[30]}$ stated that restoration of normal epicardial blood flow is not enough to allow adequate myocardial reperfusion; the latter need perfusion at the level of microcirculation and myocytes. So MBG post PPCI was analyzed also by our study.

Interestingely, the present study showed high statistical significant difference between the study groups regarding post PPCI MBG with higher incidence of MBG $376 \%$ in group (I): no LV remodeling versus only $31.4 \%$ in LV remodeling group (II) denoting that although group (II) who showed higher incidence of 
TIMI 3 post PPCI( restored epicardial reperfusion) indeed showed lower incidence of MBG 3 (failed to restore microvascular and myocytes reperfusion ). This confirming fact mentioned above by Ito et al ${ }^{[30]}$.This finding was concordant with Bastawy et al ${ }^{[25]}$ who found significant difference in his study groups regarding $\mathrm{MBG} 3$ with worsened MBG post PPCI in LV remodeling group.

The present study showed that with multivariate logestic regression analysis GLS was an independent predictor of LV remodeling after acute STEMI treated by primary PCI, this was concordant with Huttin et al ${ }^{[31]}$ who emphasized on the role of GLS in predicting $\mathrm{LV}$ remodeling after myocardial infarction. He concluded that there is a strong association between GLS and adverse remodeling.

\section{CONCLUSIONS}

Our study found that GLS was an independent predictor of adverse LV remodeling early after MI at a cut-off value - $15.6 \%$ and so GLS might be used for early risk stratification of acute STEMI patient treated with primary PCI.

\section{Limitations}

The major limitations of the present study are that it is based on a single-center experience and may be limited by the small number of patients.

\section{Declaration of interest}

The authors report no conflicts of interest. The authors alone are responsible for the content and writing of the paper.

Funding information

None declared

\section{REFERENCES}

(1) Cohn JN, Ferrari R, Sharpe Net al. Cardiac remodeling - concepts and clinical implications: a consensus paper from an international forum on cardiac remodeling. Behalf of an International Forum on Cardiac Remodeling. J Am CollCardiol. 2000;35:569-582

(2) Guidry UC, Evans JC, Larson MG et al. Temporal trends in event rates after Q-wave myocardial infarction: the Framingham Heart Study. Circulation. 1999;100:2054-2059.

(3) El Aidi H, Adams A, Moons KG) :. Cardiac magnetic resonance imaging findings and the risk of cardiovascular events in patients with recent myocardial infarction or suspected or known coronary artery disease: a systematic review of prognostic studies. J

Am CollCardiol. 2014;63:1031-1045.

(4) Coppola G, Carità P, Corrado E et al. ST segment elevations: Always a marker of acute myocardial infarction?Italian Study Group of Cardiovascular Emergencies of the Italian Society of Cardiology.Indian Heart J. 2013;65(4):412-23. Review

(5) Brener SJ, Dizon JM, Mehran $R$ et al. Complementary prognostic utility of myocardial blush grade and ST-segment resolusion after primary percutaneus coronary intervention analysis from HORIZON -AMI trial.Am Heart J.2013;166676-83

(6)Ding S, Zhao H, Qiao ZQ et al. Early resolution of STsegment elevation after reperf usion therapy for acute myocardialinfarction:Its relat ion to echocardiography-

determined left ventricular global and regionalfuncti on and deformation.J Electrocardiol.2015;48(2):2418

(7)Yancy, CW, Jessup M, Bozkurt B, et al. ACC/AHA/HFSA Focused Update of the 2013 ACCF/AHA Guideline for the Management of Heart Failure: A Report of the American College of Cardiology/American Heart Association Task Force on Clinical Practice Guidelines and the Heart Failure Society of America. 2017, Volume 136, Issue 2.

(8) Albin G, Rohko and Rademark E. Comparison of echocardiographic quantification of left ventricular ejection fraction to radio nucleotide angiography in patients with regional wall motion abnormalities. Am.J.Cardiol. 1990; 65:103.

(9) Bochenek T, Wita K, Tabor $\mathbf{Z}$ et al. Value of Speckle-Tracking Echocardiography for Prediction of Left Ventricular Remodeling in Patients with STElevation Myocardial Infarction Treated by Primary Percutaneous Intervention. J Am Soc Echocardiogr.2011;24(12):1342-8

(10) Schirmer H, Lunde P, Rasmussen $K$ et al. Mitral flow derived Doppler indices of left ventricular diastolic function in a general population; the Tromso study. Eur Heart J. 2000 Aug;21(16):1376-86.

(11) Garbi M, Edvardsen T, Bax $\mathbf{J}$ et al. EACVI appropriateness criteria for the use of cardiovascular imaging in heart failure derived from European National Imaging Societies voting.Eur Heart J Cardiovasc Imaging.2016;17(7):711-21. Review.

(12) Lancellotti P, Price $S$, Edvardsen $T$ et al. The use of echocardiography in acute cardiovascular care: Recommendations of the European Association of Cardiovascular Imaging and the Acute Cardiovascular Care Association . Eur Heart J Acute Cardiovasc Care.2015 ;4(1):3-5.

(13)Plewka M, Kasprzak JD, Wierzbowska-Drabik K et al. Variability of longitudinal strain in left ventricular seg ments supplied by nonstenosedcoronaryartery: 
insights from speckle tracking analysis of dobutamine stress echocardiograms in patients with high coronary risk profile.Arch Med Sci.2017 1; 13 (1): 82-92

(14) Lang RM, Badano LP, Mor-AviV et al. Recommendations

for cardiac chamber quantification by echocardiograp hy in adults:an updatefromthe AmericanSociety ofEc hocardiography andthe European Association of Card iovascularImaging.EurHeartJCardiovasc Imaging.2015; 16(3):233-70.

(15) Wijns W, Kolh P, Danchin N., et al . Guidelines on myocardial revascularization. Task Force on Myocardial Revascularization of the European Society of Cardiology (ESC) and the European Association for Cardio-Thoracic Surgery (EACTS); European Association for Percutaneous Cardiovascular Interventions (EAPCI), Eur Heart J. 2010; 31(20):2501-2555

(16)Ahmed N, Carberry J, Teng V et al. Risk assessment in patients with an acute ST-elevation myocardial infarction. J Comp Eff Res.2016;5(6):581-593.

(17) West JA, Morise A, Atwood JE et al. An agreement approach to predict severe angiographic CAD with clinical and exercise test data. Am Heart J.1997; 134 (4):672-9.

(18) Piro M, Della Bona R, Abbate: Sex related differences in myocardial remodeling. J Am Coll Cardiol.2010.;55(11):1057-65.

(19)Carrick D, Haig C, Rauhalammi S et al. Pathophysiology of LV Remodeling in Survivors of STEMI : Inflammation, Remote Myocardium, and Prognosis. JACC CardiovascImaging(2015). 1;8(7):779-89.

(20) Feldman LJ, Coste P, Furber A, et al Incomplete resolution of ST-segment elevation is a marker of transient microcirculatory dysfunction after stenting for acute myocardial infarction. Circulation(2003):;107:2684-9.

(21) Amaya N, Nakano A, Uzui H et al.Relationship between microcirculatory dysfunction and resolution of ST-segment elevation in the early phase after primary angioplasty in patients with ST-segment elevation myocardial infarction.Int J Cardiol.2012;159(2):144-9.

(22) Na HM, Cho GY, Lee JM et al: Echocardiographic Predictors for Left Ventricular Remodeling after Acute ST Elevation Myocardial Infarction with Low Risk Group: Speckle Tracking
Analysis .J Cardiovasc Ultrasound.2016 ;24(2):12834

(23)LópezHaldón J, Fernández Quero $M$ et al: Value of NTProBNP level and echocardiographic pa rameters in STsegment elevation myocardialinfarcti on treated by primary angioplasty: relationships bet weenthese variables andtheir usefulness as predictor $\mathrm{s}$ of ventricular remodeling.RevEspCardiol.2010 ;63(9):1019-27.

(24)Sugano A, Seo Y, Ishizu T et al .Value of 3Dimensional Speckle Tracking Echocardiography in the Prediction of Microvascular Obstruction and Left Ventricular Remodeling in Patients With STElevation Myocardial Infarction AkinoriSugano,Circ J.2017;81(3):353-36

(25)Bastawy I, Ismail M , El Kilany W et al: Speckle tracking imaging as a predictor of left ventricular remodeling 6 months after first anterior ST elevation myocardial infarction in patients managed by primary percutaneous coronary intervention . 2018The Egyptian Heart Journal

(26)Bonios MJ, Kaladaridou A, Tasoulis A et al:Value of apical circumferential strain in the early post-myocardial infarction period for prediction of left ventricular remodeling. Hellenic J Cardiol.2014;55(4):305-12.

(27) Xu L, Huang X, Ma J et al .Value of threedimensional strain parameters for predicting left ventricular remodeling after ST-elevation myocardial infarction. Int $\mathrm{J}$ Cardiovasc Imaging.2017;33(5):663-673

(28)Khurelsukh K, Kim YH, Seon HJ et al :Noncontrast cardiac CT immediately after percutaneous coronary intervention: does it predict the risk of left ventricular remodeling in patients with ST-elevation myocardial infarction? Int $\mathrm{J}$ Cardiovasc Imaging2016:;32Suppl 1:147-54.

(29)de Prado AP, Fernández-Vázquez F, CuellasRamón JC et al :Coronary Angiography: Beyond Coronary AnatomyRev Esp Cardiol.2006;59 (6) :596-608 -

(30)Ito H, Maruyama A, Iwakura K et al:clinical implication of the no reflow phenomenon; apredictor of complication and left ventricular remodeling Circulation. 1996.,15;93(2):223-8

(31)Huttin O, Coiro S, Selton-Suty $C$ et al :Prediction of Left Ventricular Remodeling after a Myocardial Infarction: Role of Myocardial Deformation: A Systematic Review and MetaAnalysis PLoS One. 2016;11(12):e0168349. 